\title{
Nonsuppressed ion chromatographic determination of total calcium in milk
}

\author{
S. Rahimi-Yazdi, ${ }^{*}$ M. A. Ferrer, ${ }^{*} \dagger$ and M. Corredig ${ }^{* 1}$ \\ *Department of Food Science, University of Guelph, Guelph, Ontario N1H 2W1, Canada \\ †Department of Nutrition and Dietetics, University of Zulia, Maracaibo, Venezuela, 4005
}

\section{ABSTRACT}

A novel approach for measuring calcium in milk by the use of high performance nonsuppressed ion chromatography is proposed. Total calcium as well as the calcium present in the colloidal and salt state in milk can be quantified. Because the presence of citrate in the milk serum interferes with the measurement of calcium by the conductivity detector, the free and chelated calcium can also be distinguished. By using a sample preparation procedure using Amberlite resin (Fluka, Steinheim, Germany), the amount of soluble calcium in milk can be determined. Because the quantification of calcium in milk and milk derivatives is becoming increasingly important in order to understand the functionality of the milk proteins, better methods need to be developed to determine, with a high level of accuracy, the amount of calcium present in milk in various forms.

Key words: high performance nonsuppressed ion chromatography, total calcium, free calcium, citrate

\section{INTRODUCTION}

Milk is a colloidal dispersion containing proteins and fat globules. Milk is also a good source of calcium, sodium, magnesium, potassium, selenium, and zinc, as well as chloride and the anions of citrate and phosphate, typically in the 5 to $40 \mathrm{~m} M$ concentration range (Holt, 1985). The mineral content of bovine milk is not constant and many factors (e.g., environmental and genetic factors, nutrition of the animal, and so forth) affect the mineral composition (Holt, 1997). Each salt is partitioned between the diffusate and the colloidal phases and the species concentrations in each phase depend on multiple ion equilibrium (Holt et al., 1981; Gaucheron et al., 1996). The principal anions present in milk are phosphate (inorganic, organic, and covalently bound to the casein proteins), citrate (10\% linked to casein micelles and the rest in aqueous phase), and

Received June 2, 2009.

Accepted January 7, 2010.

${ }^{1}$ Corresponding author: mcorredi@uoguelph.ca chloride (mostly present in the aqueous phase; Holt, 1997).

It has been shown that salts in milk are partitioned between diffusible and nondiffusible fractions. The great majority of the nondiffusible salts are in the form of colloidal calcium phosphate or, preferably, micellar calcium phosphate. It has been established that micellar calcium phosphate particles are several nanometers in size, that they are formed from an amorphous hydrated calcium phosphate linked to casein phosphate centers, and that they are distributed throughout the protein matrix of casein micelles (Holt, 2004). These nuclei of amorphous dicalcium phosphate are also called calcium phosphate nanoclusters. It has been previously reported that there are about 800 such calcium phosphate particles in a casein micelle of $100-\mathrm{nm}$ radius (Holt et al., 1998; Marchin et al., 2007). Because the $\alpha_{\mathrm{S1}^{-}}$and $\alpha_{S 2}$-caseins contain more than 1 phosphate center per molecule, there is considerable scope for cross-linking a substantial proportion of caseins in the micelle (Holt, 2004). In the past few years, increasing attention has been focused on the ionic equilibrium present in milk because the levels of calcium, phosphate, and other salts strongly affect, among other things, the processing functionality of milk proteins.

Several methods are routinely employed for measuring the concentration of total calcium in milk and milk serum, such as atomic absorption spectrometry, spectrophotometry, fluorometry, complexometric titration, flame photometry, and inductively coupled plasma-emission spectroscopy. Each of these methods has specific acceptable accuracy and precision, possible sources of error, and interfering agents (Robertson and Marshall, 1979; Silva et al., 1997). Inductively coupled plasma-emission spectroscopy has been adapted to perform routine, simultaneous, direct analyses of calcium, magnesium, copper, zinc, and iron in milk, juices, and several biological fluids (Nixon et al., 1986; Nobrega et al., 1997; McKinstry et al., 1999). This technique can be applied to a wide range of samples, and the samples undergo several preparation steps (for example, dry digestion) to eliminate or minimize the risk of contamination and analyte loss. Sample preparation methods such as wet mineralization are also common, based on 
the oxidizing action of strong acids in specific microwave ovens; these methods also require long preparation times (Moreno-Torres et al., 2000).

Ion chromatography (IC) is also often used to measure inorganic anions and cations, transition metals, organic acids, amines, phenols, surfactants, and sugars based on their conductivity, amperometry, or fluorescence (Weiss, 1995). To employ IC to measure the total calcium in milk, sample preparations need to be carried out to change all the calcium forms in milk to free (ionized) calcium because the measurements are based on $\mathrm{Ca}^{2+}$ conductance.

The objective of this work was to develop a procedure to analyze calcium in milk using nonsuppressed ion chromatography. In particular, the interference of diand tricarboxylic acid (citrate anions in this particular case) in measuring the amount of calcium was evaluated and a sample preparation method was devised to avoid interferences.

\section{MATERIALS AND METHODS}

\section{Materials}

Calcium standard for IC TraceCERT $(1,000 \mathrm{mg} / \mathrm{L}$ of $\mathrm{Ca}^{2+}$ in $\mathrm{HNO}_{3}$; Fluka, Sigma, Steinheim, Germany) was used as certified reference material to prepare external standard solutions. Dicarboxylic acids $[\mathrm{L}(+)$-tartaric acid 99+\% (Acros Organics, Geel, Belgium) and pyridine-2, 6-dicarboxylic acid 99.0\% (Acros Organics)] were used without further purification. To prepare the eluent as mobile phase in IC system, an aqueous solution of $4 \mathrm{~m} M$ of tartaric acid and $1 \mathrm{~m} M$ pyridine-2, 6 -dicarboxylic acid was made in 1 volumetric flask; the $\mathrm{pH}$ of this solution was 2.7. Nitric acid (Fisher Scientific, Mississauga Ontario, Canada) was used to make up a solution of $2 \mathrm{~m} M$ nitric acid as the system acceptor. All the solutions were prepared with HPLC grade submicron-filtered water (W5-4, Fisher Scientific). Hydrochloric acid (Fisher Scientific) was used to make a solution of $1 \mathrm{M}$ acid for protein precipitation and for adjusting the $\mathrm{pH}$. Sodium hydroxide pellets (Fisher Scientific) and sodium chloride $99.8 \%$ biological certified crystalline (Fisher Scientific) were used to make the activation solution for the anion exchange resin. Calcium chloride, dihydrate $100.1 \%$ reagent ACS, and citric acid monohydrate-100.1\% (Fisher Scientific) were also used.

\section{Sample Preparation}

Fresh milk was collected from the Ponsonby Research Station of the University of Guelph (Guelph, Ontario, Canada) and sodium azide $[0.02 \%$ (wt/vol)] was im- mediately added to prevent bacterial growth. The raw milk was skimmed at $6,000 \times g$ for 20 min at $4^{\circ} \mathrm{C}$ in a Beckman Coulter centrifuge (model J2-21, Beckman Coulter, Mississauga, Ontario, Canada) and filtered 3 times through Whatman glass fiber filters (Fisher Scientific). Permeates were prepared using a laboratory scale ultrafiltration cartridge (Millipore CDUF001LG, Fisher Scientific) with a nominal cut-off of 10,000 Da and a nominal area of $0.095 \mathrm{~m}^{2}\left(1 \mathrm{ft}^{2}\right)$.

To measure the total calcium concentration in milk, aliquots $(666 \mu \mathrm{L})$ of milk were directly acidified with $200 \mu \mathrm{L}$ of $1 M$ hydrochloric acid to precipitate the proteins and dissolve the micellar calcium phosphate. Then, HPLC grade water $(466 \mu \mathrm{L})$ was added to micro centrifuge tubes and the samples were centrifuged at $4,500 \times g$ for $15 \mathrm{~min}$ at room temperature in a benchtop Eppendorf centrifuge (model 5415 D, Eppendorf AG, Hamburg, Germany). The supernatant was collected $(666 \mu \mathrm{L})$, brought to $50 \mathrm{~mL}$ using HPLC water, and poured into polypropylene containers. The final $\mathrm{pH}$ of the samples was 3.0.

To measure the total calcium concentration in permeate samples, $1.0 \mathrm{~mL}$ of permeate was acidified directly with $100 \mu \mathrm{L}$ of $1 M$ hydrochloric acid; the mixture was then adjusted to $50 \mathrm{~mL}$ using HPLC water and poured in polypropylene containers. Separation of citrate anions available in milk was carried out using an anion exchange preparative step using Amberlite IRA958 chloride (Fluka, Steinheim, Germany), a strongly basic (type I) resin. This resin has an acrylic copolymer matrix with functional quaternary ammonium groups. The resin was packed in a glass-tube high performance column (170 $\mathrm{mm} \times 10 \mathrm{~mm}$; GE Healthcare, Waukesha, WI) with a bed volume of $5.5 \mathrm{~mL}$. The column was packed manually with $5 \mathrm{~g}$ of Amberlite slurry, and the resin was activated using $30 \mathrm{~mL}$ of $2 \% \mathrm{NaOH}$ and $10 \% \mathrm{NaCl}$ at a flow rate of $1 \mathrm{~mL} / \mathrm{min}$ using a peristaltic pump. The column was then rinsed with $50 \mathrm{~mL}$ of HPLC water at the same flow rate. The diluted sample was then pumped through the column at a rate of $1 \mathrm{~mL} / \mathrm{min}$ and, after discarding the first $30 \mathrm{~mL}$ of throughflow, the sample was collected for measurements by IC.

\section{Ion Chromatography}

The chromatography system used consisted of a 861 advanced compact IC (Metrohm ion analysis, Metrohm Ltd., Herisau, Switzerland) with injection valve, high pressure pump, peristaltic pump, and conductivity detector, all controlled by the 838 advanced sample processor (IC Net 2.3, Metrohm Ltd.). The thermostatcontrolled detector $\left(30 \pm 0.1^{\circ} \mathrm{C}\right)$ had a resolution of $0.028 \mathrm{nS} / \mathrm{cm}$ in the measurement range of the experiments (up to $50 \mu \mathrm{S} / \mathrm{cm}$ ) and a noise of $0.2 \mu \mathrm{S} / \mathrm{cm}$. 
Table 1. Solubility constants $\left(\mathrm{K}_{\mathrm{sp}}\right)$ of soluble salts in milk serum at $25^{\circ} \mathrm{C}^{1}$

\begin{tabular}{lll}
\hline Item & Chemical formula & \multicolumn{1}{c}{$\mathrm{K}_{\mathrm{sp}}$} \\
\hline Calcium citrate & $\mathrm{Ca}_{3} \mathrm{Citrate}_{2}$ & $2.3 \times 10^{-18}$ \\
Calcium phosphate & $\mathrm{Ca}_{3}\left(\mathrm{PO}_{4}\right)_{2}$ & $2.07 \times 10^{-33}$ \\
Calcium carbonate & $\mathrm{CaCO}_{3}$ & $3.36 \times 10^{-9}$ \\
Calcium sulfate & $\mathrm{CaSO}_{4}$ & $4.93 \times 10^{-5}$ \\
\hline
\end{tabular}

${ }^{1}$ Derived from Walstra, 1999; Skoog et al., 2000.

Samples were prepared in line by the use of a 833 IC liquid handling dialysis unit (Metrohm Ltd.). This unit contained a 2-channel peristaltic pump and a dialysis cell containing a $0.2-\mu \mathrm{m}$ cellulose acetate membrane (Fisher Scientific). The samples were placed in polypropylene sample vessels on a sample rack of the 838 advanced sample processor (Metrohm Ltd.). Before sample injection, at least 5 standard solutions with different concentrations of calcium (concentrations from 1-10 mg/L) were loaded. Samples of milk and permeate were diluted 1:150 and 1:50, respectively. The samples were transferred by the peristaltic pump of the 838 advanced sample processor to the dialysis unit at the flow rate of $1.27 \mathrm{~mL} / \mathrm{min}$ in $5.5 \mathrm{~min}$ and the acceptor was also transferred by the peristaltic pump of the 833 IC dialysis unit to the other side at the same flow rate. The carrier was $2 \mathrm{~m} M$ nitric acid. The ions were therefore transferred to the stationary acceptor solution and then injected directly into the 861 advanced compact IC, whereas other particles were excluded. As a result of this special stopped-flow technique, $100 \%$ sample recovery could be achieved in the acceptor solution and it was possible to carry out calibration with external standards. The enriched solution was injected in a $20-\mu \mathrm{L}$ loop.

Before running, the separation column (Metrosep C2 150/40 packed with 7- $\mu \mathrm{m}$ silica gel, Metrohm Ltd.) was preequilibrated with the eluent for $45 \mathrm{~min}$ using $1 \mathrm{~mL} /$ min at $30 \pm 0.1^{\circ} \mathrm{C}$, with an operating pressure never exceeding 9.2 $\mathrm{MPa}$. The dialysis unit was then turned on for $30 \mathrm{~min}$ to equilibrate the system and flush any air bubbles. Statistical analysis was performed using

Table 2. Calcium concentration $(\mathrm{m} M)$ in milk and permeate samples after acidification, as measured using different techniques

\begin{tabular}{lrcc}
\hline Sample & \multicolumn{1}{c}{$\mathrm{IC}^{1}$} & $\mathrm{AAS}^{2}$ & $\mathrm{ICP}^{2} \mathrm{ES}^{3}$ \\
\hline Skim milk & $24.75 \pm 0.19$ & $31.53 \pm 0.53$ & $30.75 \pm 0.63$ \\
Permeate & $5.29 \pm 0.78$ & $9.93 \pm 0.1$ & - \\
\hline
\end{tabular}

${ }^{1}$ Ion chromatography (average of 9 measurements).

${ }^{2}$ Atomic absorption spectroscopy (average of 8 measurements). From De la Fuente and Juarez, 1995; De la Fuente et al., 1998.

${ }^{3}$ Inductively coupled plasma-emission spectroscopy (average of 8 measurements). From McKinstry et al., 1999.
Table 3. Constants for the formation of calcium citrate, tartrate, and dipicolinate complexes at $25^{\circ} \mathrm{C}$

\begin{tabular}{lccc}
\hline & \multicolumn{3}{c}{ Binding constant } \\
\cline { 2 - 4 } Acid & $\log \mathrm{K}_{1}$ & $\log \mathrm{K}_{2}$ & $\log \mathrm{K}_{3}$ \\
\hline Citric $^{1}$ & $3.63 \pm 0.05$ & $2.03 \pm 0.04$ & $1.05 \pm 0.09$ \\
Tartaric $^{2}$ & $1.98 \pm 0.02$ & $1.18 \pm 0.02$ & - \\
Dipicolinic $^{3}$ & $4.39 \pm 0.01$ & $2.25 \pm 0.01$ & - \\
\hline${ }^{1}$ Pearce, 1980. & & \\
${ }^{2}$ Zelenina and Zelenin, 2005. \\
${ }^{3}$ Tang et al., 1968.
\end{tabular}

S-PLUS software (Insightful Corp., TIBCO Software Inc., Palo Alto, CA).

\section{RESULTS AND DISCUSSION}

In cow milk, about one-third of the total calcium is present in soluble form, whereas the rest is in a colloidal form as an integral part of the phosphate nanoclusters holding the casein micelles (Holt et al., 1981). Therefore, to be accurately determined in milk, the calcium salts bound to the phosphoserine residues of the casein proteins need to be dissociated from the casein micelles. Moderately diluted acid $(1 \mathrm{M} \mathrm{HCl})$ was applied at room temperature to acidify the milk to $\mathrm{pH}$ below 4.6. This induced casein aggregation and the dissociation of the calcium phosphate from the protein assemblies (Fox and McSweeney, 1998). At pH 3.0, the aqueous phase contains calcium salts, each with a specific solubility constant, as shown in Table 1 (Walstra, 1999; Skoog et al., 2000). These salts, poorly soluble in water, have an increased solubility at low $\mathrm{pH}$, with the presence of an excess of positive hydrogen ions; therefore, free calcium can be measured. At each $\mathrm{pH}$, however, a dynamic equilibrium is established between the dissolved and undissolved and the dissociated and the associated salts. Table 2 summarizes the data obtained after direct acidification of milk and permeate using $1 \mathrm{M}$ $\mathrm{HCl}$. The results obtained using ion chromatography showed a lower amount of total calcium in permeate and milk compared with the data reported in the literature obtained using atomic adsorption spectroscopy or inductively coupled plasma-emission spectroscopy (De la Fuente and Juarez, 1995; De la Fuente et al., 1998; McKinstry et al., 1999). The smaller value determined by IC is related to the association of cations with anions such as phosphate and citrate.

During the analysis, the sample solution containing the ions was pumped through the dialysis unit. The strong gradient of concentration and the nitric acid carrier $(2 \mathrm{mM})$ prevented any entrapment of ions on the membrane, and all ions were pumped, with a steady- 
Table 4. Total calcium concentrations determined by ion chromatography for a $\mathrm{CaCl}_{2}$ solution (10 $\left.\mathrm{mg} / \mathrm{L}\right)$ and the same solution containing $7 \mathrm{~m} M$ citric acid ${ }^{1}$

\begin{tabular}{lccc}
\hline Sample & Retention time $(\mathrm{min})$ & Concentration $(\mathrm{mg} / \mathrm{L})$ & Relative percentage $^{2}$ \\
\hline Calcium chloride & $9.85 \pm 1$ & $9.96 \pm 0.15$ & 100.0 \\
Calcium chloride + citric acid & $9.85 \pm 1$ & $7.68 \pm 0.28$ & 78.5 \\
\hline
\end{tabular}

${ }^{1}$ Results are the average of 5 replicate samples.

${ }^{2}$ Based on peak area.

state flow, in the separation column. The mobile phase comprised 2 dicarboxylic acids, tartaric acid $\left(\mathrm{p} K_{\mathrm{a} 1} 3.036\right.$ and $\mathrm{p} K_{\mathrm{a} 2} 4.366$ at $\left.25^{\circ} \mathrm{C}\right)$, and dipicolinic acid $\left(\mathrm{p} K_{\mathrm{a} 1}\right.$ 2.06 and $\mathrm{p} K_{\mathrm{a} 2} 4.58$ at $25^{\circ} \mathrm{C}$ for the first and second dissociation constant $\mathrm{p} K \mathrm{a}_{1}$, and $\mathrm{p} K \mathrm{a}_{2}$, respectively). These 2 organic acids chelated the cations bound to the carboxyl groups of the silica gel and carried them to the detector. Existing inorganic acids in milk and permeate such as lactic and citric acid were also carried through the dialysis membrane and would not bind to the functional group of the column. On the other hand, to accurately measure the calcium conductance, the ion should be in its free form $\left(\mathrm{Ca}^{2+}\right)$. Table 3 illustrates the complexing constants of calcium with citric, tartaric, and dipicolinic acid. It is clear that citric acid, being a tricarboxylic acid, is a stronger chelator than the eluent acids used in the mobile phase, and for this reason the amount of $\mathrm{Ca}^{2+}$ measured by conductivity detector was underestimated.

To prove that the presence of citrate in milk and permeate samples affects the detection of calcium when using ion chromatography with conductivity detection, solutions of $10 \mathrm{mg} / \mathrm{L}$ of calcium from calcium chloride, or the same solution mixed with $7 \mathrm{~m} M$ citric acid, were prepared. Table 4 shows the amount of calcium quantified in the 2 samples. The results clearly indicate that the amount of calcium ions detected in the presence of citrate was underestimated. In addition, it is important to note that the presence of citrate did not affect the retention time of the calcium peak.

A sample preparation method was therefore developed to eliminate as much as possible the interference from citrate anions by using an anionic exchange resin. The samples were then treated by passing them through a column packed with Amberlite IRA958 chloride. The Amberlite anion exchange resins have been previously employed as organic scavengers for the adsorption of naturally occurring organic anions from liquids such as surface water (Humbert et al., 2005). The quaternary ammonium residues in Amberlite IRA958 have high affinity for negatively charged ions (Gelb et al., 1985; Dietrich, 1993). This pretreatment method will separate all anions in the sample.
Figure 1 illustrates typical chromatographic profiles for cations in acidified milk, either untreated or treated with Amberlite resin. Although in the present work we focused on the determination of calcium, it is clear from the chromatograms that all the main cations in milk were well separated. The retention times were not affected by the treatment of the samples with Amberlite, although the areas were much higher for samples pretreated to eliminate the citrate interference. Figure
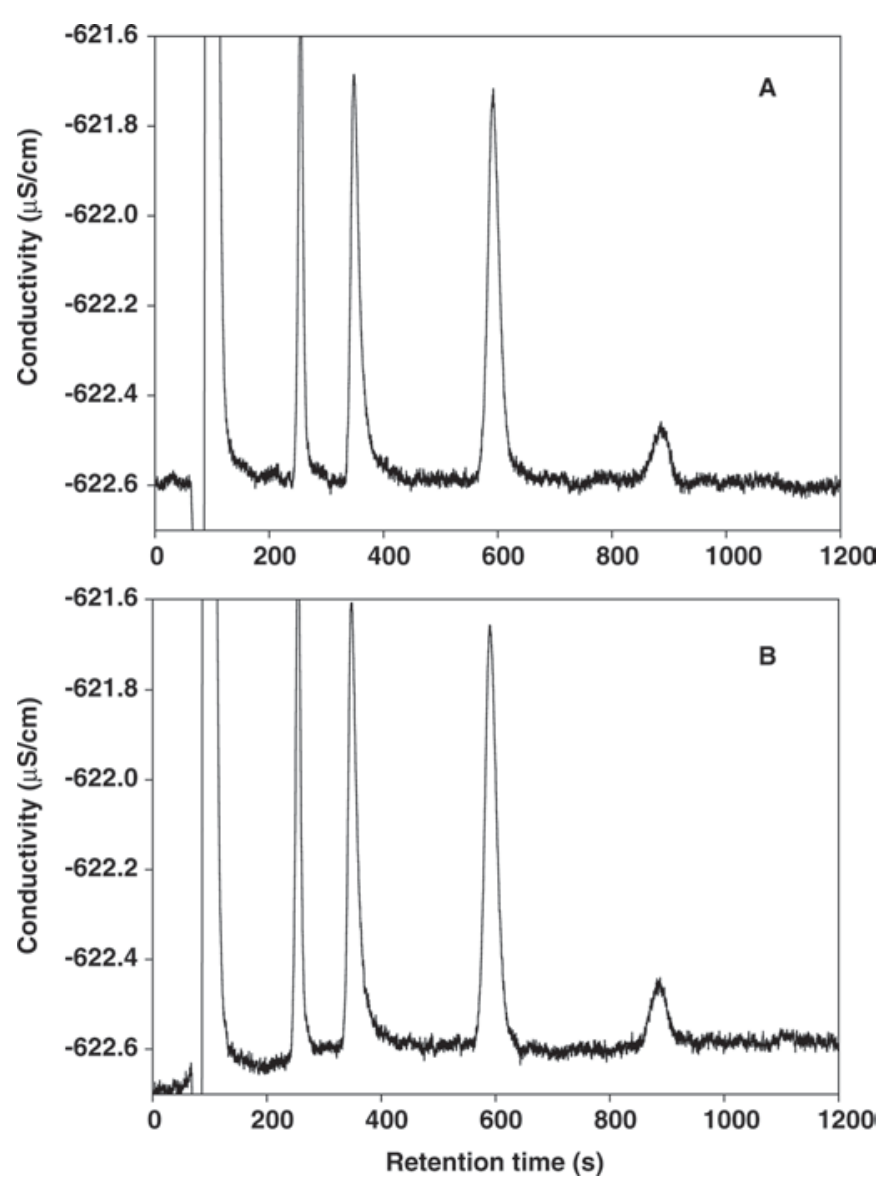

Figure 1. Typical chromatographic profiles for acidified milk A) untreated or B) treated with Amberlite resin (Fluka, Steinheim, Germany). Peak eluting at $250 \mathrm{~s}: \mathrm{Na}^{+}$; peak at $350 \mathrm{~s}: \mathrm{K}^{+}$; peak at 600 s: $\mathrm{Ca}^{2+} ;$ peak at $900 \mathrm{~s}: \mathrm{Mg}^{2+}$. 


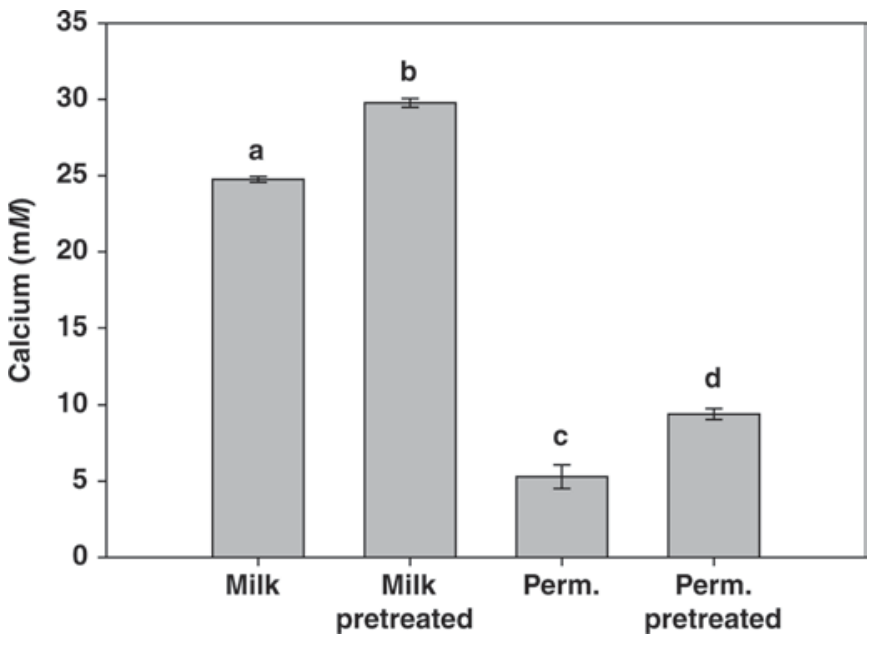

Figure 2. Total calcium concentrations determined by ion chromatography for milk and milk permeate from samples untreated or treated with Amberlite resin (Fluka, Steinheim, Germany). Values are means of 9 determinations. Averages with different letters differ significantly $(P<0.05)$.

2 clearly shows the differences in the total calcium concentration detected in milk and permeate samples and the effect of the pretreatment with the anion exchange resin. In both milk and permeate cases, statistical analysis on 9 replicate samples demonstrated a significantly higher value of calcium ions in the treated samples. The values of calcium measured after the pretreatment were in agreement with those reported in the literature from milk and milk serum.

\section{CONCLUSIONS}

Nonsuppressed ion chromatography is a high performance method well suited to measure calcium in milk and milk serum. The values of calcium determined using this method were well in agreement with those reported in the literature. Although some sample preparation needs to be carried out, the most important advantage of this method is the elimination of the ashing step and the consumption of oxidizing agents (such as nitric acid). In addition, the method allows for a high throughput, as long as the samples undergo a simple preparation step, to eliminate the citrate interference. Although the present research focused mostly on calcium ions, the chromatographic method also separated other cations in milk well. However, further research is needed to determine whether this methodology can be applied to quantify the other cations present in milk.

\section{ACKNOWLEDGMENTS}

We express our special thanks to Francesco Bonomi (University of Milan, Italy) for his insightful com- ments. This work was partly funded by the Ontario Dairy Council (Mississauga, Ontario, Canada) and the Natural Sciences and Engineering Council of Canada (Ottawa, Ontario, Canada).

\section{REFERENCES}

De la Fuente, M. A., and M. Juarez. 1995. Rapid determination of calcium, magnesium, sodium and potassium in milk by flame atomic spectrometry after microwave oven digestion. Analyst (Lond.) 120:107-111.

De la Fuente, M. A., A. N. Olano, and M. Juarez. 1998. Effects of heat treatments and subsequent storage on the mineral balance of ewes' milk. J. Dairy Res. 65:457-464.

Dietrich, B. 1993. Design of anion receptors-Application. Pure Appl. Chem. 65:1457-1464.

Fox, P. F., and P. L. H. McSweeney. 1998. Dairy Chemistry and Biochemistry. Blackie Academic \& Professional, New York, NY.

Gaucheron, F., Y. LeGraet, M. Piot, and E. Boyaval. 1996. Determination of anions of milk by ion chromatography. Lait 76:433-443.

Gelb, R. I., B. T. Lee, and L. J. Zompa. 1985. Hexacyclen complexes of anions.2. Bonding forces, structures, and selectivity. J. Am. Chem. Soc. 107:909-916.

Holt, C. 1985. The milk salts: Their secretion, concentrations and physical chemistry. Pages 143-181 in Developments in Dairy Chemistry. Lactose and Minor Constituents. Vol. 3. 1st ed. P. F. Fox, ed. Elsevier Applied Science Publishers, London, UK.

Holt, C. 1997. The milk salts and their interaction with casein. Pages 234-256 in Advanced Dairy Chemistry. Lactose, Water, Salts, and Vitamins. Vol. 3. 2nd ed. P. F. Fox, ed. Chapman \& Hall, London, UK.

Holt, C. 2004. An equilibrium thermodynamic model of the sequestration of calcium phosphate by casein micelles and its application to the calculation of the partition of salts in milk. Eur. Biophys. J. 33:421-434.

Holt, C., D. G. Dalgleish, and R. Jenness. 1981. Calculation of the ion equilibria in milk diffusate and comparison with experiment. Anal. Biochem. 113:154-163.

Holt, C., P. A. Timmins, N. Errington, and J. Leaver. 1998. A coreshell model of calcium phosphate nanoclusters derived from sedimentation equilibrium and small angle X-ray and neutron scattering measurements. Eur. J. Biochem. 252:73-78.

Humbert, H., H. Gallard, H. Suty, and J. P. Croue. 2005. Performance of selected anion exchange resins for the treatment of a high DOC content surface water. Water Res. 39:1699-1708.

Marchin, S., J. L. Putaux, F. Pignon, and J. Leonil. 2007. Effects of the environmental factors on the casein micelle structure studied by cryo transmission electron microscopy and small-angle $\mathrm{x}$-ray scattering/ultrasmall-angle x-ray scattering. J. Chem. Phys. doi:10.1063/1.2409933.

McKinstry, P. J., H. E. Indyk, and N. D. Kim. 1999. The determination of major and minor elements in milk and infant formula by slurry nebulisation and inductively coupled plasma optical emission spectrometry (ICP-OES). Food Chem. 65:245-252.

Moreno-Torres, R., M. Navarro, M. D. Ruiz-Lopez, R. Artacho, and C. Lopez. 2000. A mineralization procedure for determining magnesium in milk. Lebensm. Wiss. Technol. 33:397-400.

Nixon, D. E., T. P. Moyer, P. Johnson, J. T. Mccall, A. B. Ness, W. H. Fjerstad, and M. B. Wehde. 1986. Routine measurement of calcium, magnesium, copper, zinc, and iron in urine and serum by inductively coupled plasma emission-spectroscopy. Clin. Chem. 32:1660-1665.

Nobrega, J. A., Y. Gelinas, A. Krushevska, and R. M. Barnes. 1997. Direct determination of major and trace elements in milk by inductively coupled plasma atomic emission and mass spectrometry. J. Anal. At. Spectrom. 12:1243-1246.

Pearce, K. N. 1980. Formation constants for magnesium and calcium citrate complexes. Aust. J. Chem. 33:1511-1517. 
Robertson, W. G., and R. W. Marshall. 1979. Calcium measurements in serum and plasma-Total and ionized. CRC Crit. Rev. Clin. Lab. Sci. 11:271-304.

Silva, P. R. M., J. G. Dorea, and G. R. Boaventura. 1997. Multielement determination in small samples of human milk by inductively coupled plasma atomic emission spectrometry. Biol. Trace Elem. Res. 59:57-62.

Skoog, D. A., D. M. West, F. J. Holler, and S. R. Crouch. 2000. Analytical Chemistry. An Introduction. Emily Barrosse, New York, NY.

Tang, T., K. S. Rajanand, and N. Grecz. 1968. Mixed chelates of $\mathrm{Ca}$ (II)-Pyridine-2,6-dicarboxylate with some amino acids related to bacterial spores. Biophys. J. 8:1458-1474.
Walstra, P. 1999. Dairy Technology: Principles of Milk Properties and Processes. Marcel Dekker Inc., New York, NY.

Weiss, J. 1995. Ion Chromatography. VCH Verlagsgesellschaft mbH, Weinheim, Germany.

Zelenina, T. E., and O. Y. Zelenin. 2005. Concentration and thermodynamic stability constants of magnesium(II) and calcium(II) tartrate complexes in aqueous solutions. Russ. J. Coord. Chem. 31:623-626. 